\title{
Effects of age of diagnosis and dietary compliance on growth parameters of patients with celiac disease
}

\author{
Atakan Comba, M.D. ${ }^{a}$, Gönül Çaltepe, M.D. , Assoc. Prof. ${ }^{a}$, Özlem Yüce, M.D. ${ }^{a}$, \\ Esra Eren, M.D. ${ }^{a}$ and Ayhan G. Kalaycı M.D. Prof. ${ }^{a}$
}

\begin{abstract}
Introduction. The objective of this study was to evaluate the relation between age at diagnosis and compliance to gluten free diet (GFD) on growth in children with celiac disease and the factors that influenced compliance to GFD.

Population and Methods. Celiac disease (CD) patients with villous atrophy followed in our hospital between January 2015 and January 2017, were included. They were classified according to diagnosis age and GFD compliance. Patients' anthropometric characteristics at diagnosis and follow-up were compared.

Results. There were 73 patients with $10.4 \pm 4.5$ years of average age, $35(47.9 \%)$ patients had a short stature at diagnosis, the ages of patients who had short stature $(7.8 \pm 4.2$ years) were higher than those who did not $(5.1 \pm 4.3$ years $)(p=0.005)$. At diagnosis, 33 $(45.2 \%)$ patients were aged $\leq 6$ years, $40(54.8 \%)$ were aged $>6$ years. The height and weight $z$-scores of patients who were diagnosed at $>6$ years of age were significantly lower than those who were diagnosed $\leq 6$ years of age both at diagnosis $(\mathrm{p}=0.01$ and 0.04$)$ and at last control $(p=0.001$ and 0.001$)$, respectively. Forty-five $(61.6 \%)$ patients were fully compliant with GFD. In comparison of anthropometric data in terms of GFD compliance, the increase in BMI and weight $\mathrm{z}$-score in the fully compliant group was found to be significantly higher when compared with the other group.

Conclusions. Delay in CD diagnosis negatively affected both the height and weight and other growth parameters. GFD compliance positively affected the patients' all growth parameters, especially weight and BMI z-score.

Key words: celiac disease, child, gluten free diet, growth, anthropometry.
\end{abstract}

http:/ / dx.doi.org/10.5546/ aap.2018.eng.248

To cite: Comba A, Çaltepe G, Yüce Ö, et al. Effects of age of diagnosis and dietary compliance on growth parameters of patients with celiac disease. Arch Argent Pediatr 2018;116(4):248-255.

\section{INTRODUCTION}

Celiac disease (CD) is a systemic autoimmune disease that develops as a result of permanent susceptibility to "gluten" in the diet of individuals who have a genetic predisposition. ${ }^{1}$ The worldwide prevalence of $C D$ is between 0.5 and $1 \% .^{2}$ In Turkey, its prevalence in a large-scale research of children was $0.47 \% .^{3}$ The clinical spectrum of the disease includes symptomatic, silent, and latent forms. Symptomatic patients may present with typical or atypical symptoms. ${ }^{4,5}$ Over the last two decades, significant changes have occurred in the admission symptoms of patients with $\mathrm{CD}$, and the prevalence of atypical and silent CD has significantly increased. ${ }^{4,6}$

A gluten-free diet (GFD) is the only treatment of CD. Catch-up growth is maximal in the first 6 months on a GFD. After the GFD starts, weight catches up more quickly than height. ${ }^{4}$ Generally, weight catches up in 6-12 months, while height catches up in 2-3 years. ${ }^{7}$ Dietary compliance also results in rapid recovery as shown in the clinical and laboratory findings of the patients. ${ }^{1,5}$

Early diagnosis helps to minimize the impact of $C D$ and optimize final adult height. ${ }^{8}$ Delays in treatment initiation for children with celiac disease are known to be associated with short stature in adulhood. ${ }^{9}$

Dietary compliance in pediatric patients is difficult, especially in adolescence. In this period, dietary compliance is often a challenge because of the child's psychological and social life. Dietary compliance in patients diagnosed within this period or in asymptomatic patients is worse when compared with patients with 
classical symptoms or patients who have been diagnosed at an early age; thus, these patients should be closely followed up. ${ }^{10}$

The objective of this study was to evaluate the relation between age at diagnosis and compliance to GFD on growth in children with celiac disease and the factors that influenced compliance to GFD.

\section{POPULATION AND METHOD}

This study was conducted at Ondokuz Mayis University Faculty of Medicine, Department of Pediatric Gastroenterology, Hepatology and Nutrition between January 2015 and January 2017. This study was approved by Hitit University Faculty of Medicine Clinical Researches Ethical Board (No:2016-54).

Celiac disease patients with villous atrophy followed in our hospital were included in the study.

Tissue transglutaminase (TG-2) IgA and antiendomysial antibody $\operatorname{Ig} \mathrm{A}$ and serum IgA levels were examined in the serum to diagnose CD. TG-2 IgG was checked in two of the patients who had IgA deficiency. TG-2 IgA and TG-2 IgG (Euroimmun, Germany) were determined with microELISA, and EMA (antiendomysial antibody) was detected using indirect immunofluorescence. For antigenic substrate, monkey distal esophagus was used. An endoscopic duodenum biopsy was performed on patients with positive antibodies by using a pediatric gastroscope (Olympus GIF Q240Z Japan). Multiple biopsy samples were obtained from the second part of the duodenum. The severity of small bowel mucosal villous atrophy was categorized based on Modified Marsh (Oberhuber) classification. Modified Marsh (Oberhuber) classification is a morphological classification used to demonstrate the effect in the intestine in cases of celiac disease and assesses intraepithelial lymphocyte increase (Marsh 1), crypt hyperplasia (Marsh 2), and villous atrophy (partial [3a], subtotal [3b], total [3c]). ${ }^{11}$ Patients with Marsh 3 lesions ( $3 a, 3 b$ and $3 c$ ) were included in the study.

The patients were grouped as typical or atypical $C D$ based on their presenting features. Patients whose referral complaints included diarrhoea were assessed as 'typical celiac', whereas patients who were referred with complaints of other GIS or non-GIS findings without diarrhoea were assessed as patients with atypical celiac disease. The sociodemographic data, anthropometric measurements, and laboratory values of the patients were recorded. Height, weight, and body mass index (BMI) scores were calculated according to CDC scales. Height for age, weight for age, and weight for height values were recorded. Short stature was defined by height for age score below -2 standard deviations.

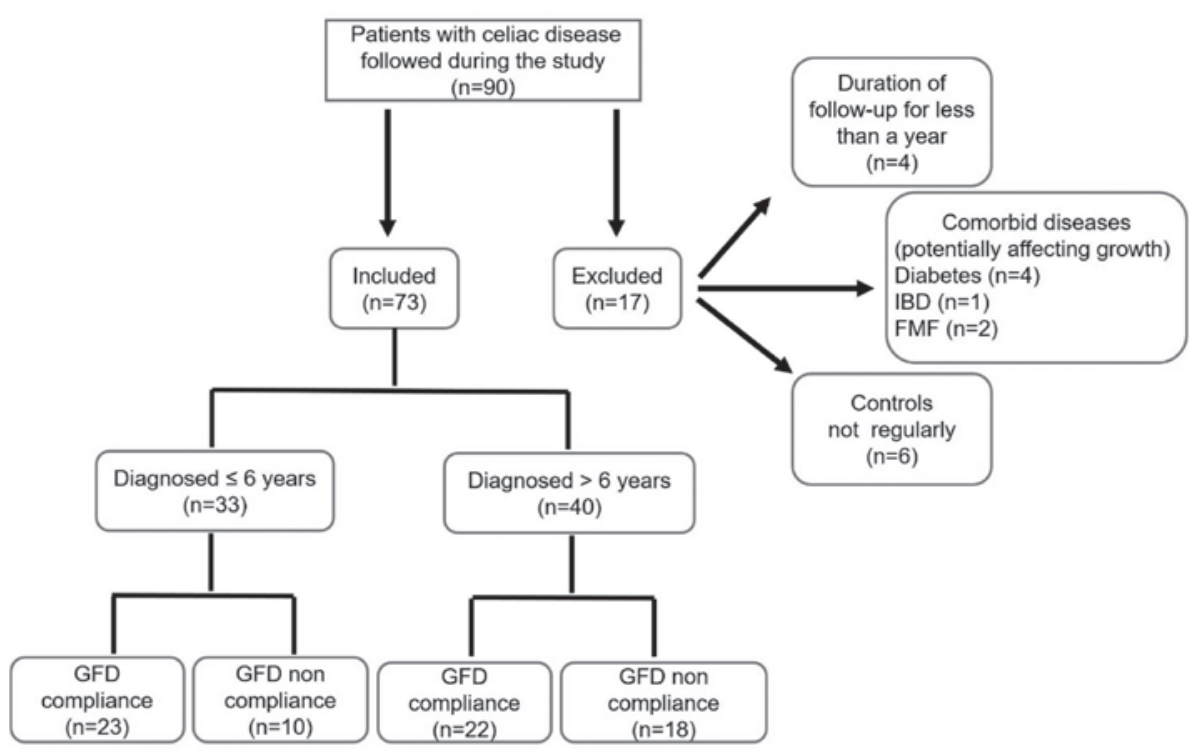

IBD: inflammatory bowel disease, GFD: gluten-free diet, FMF: familial mediterranean fever. 
Celiac antibodies were evaluated every six months. Full compliance with GFD was defined as the change of patient serology from positive to negative at the end of one year, and they were defined as non-compliant if the antibodies remained positive.

Statistical analyses were performed using SPSS version 20 . Normality tests were conducted first to compare the average values between two groups. The $t$ test was used to compare independent paired groups that showed normal distribution. In non-normally distributed data, independent paired groups were compared with the Mann-Whitney $U$ test. The paired $t$-test and Wilcoxon test were used to compare dependent paired groups that are normally and not normally distributed, respectively. The Pearson chi-square

TABLE 1. Clinical characteristics of patients $(n=73)$

\begin{tabular}{ll}
\hline Features & \multicolumn{1}{c}{$\mathbf{n ~ ( \% )}$} \\
\hline Gender & $47(64 \%)$ \\
Female & $26(36 \%)$ \\
Male & $6.4 \pm 4.4(1-15)$ \\
Diagnosis age of patients (years) & $10.4 \pm 4.5(2-17)$ \\
Current age of patients (years)* & \\
Clinical presentation & $34(46.6 \%)$ \\
$\quad$ Typical & $39(53.4 \%)$ \\
Atypical & \\
Modified Marsh classification & $20(27.4 \%)$ \\
3a & $31(42.5 \%)$ \\
3b & $22(30.1 \%)$ \\
3c & $47.2 \pm 31(12-131)$ \\
Follow up time (months)* &
\end{tabular}

${ }^{*}$ mean \pm standart deviation (range). test and $\mathrm{z}$ test were performed while comparing percentages for qualitative data. A $\mathrm{p}<0,05$ was considered statistically significant.

\section{RESULTS}

Seventy-three patients with CD confirmed by duodenal biopsy and villous atrophy were included in the study (Figure 1). The current mean age of patients was $10.4 \pm 4.5$ (range $2-17$ ) years, and 47 patients $(64.4 \%)$ were female. Thirty-four $(46.6 \%)$ of the patients had typical CD, while $39(53.4 \%)$ had atypical CD based on their presenting symptoms (Table 1). The most common symptom of atypical patients was short stature $(n=31,28.7 \%)$ while $47.9 \%$ were found to have short stature at the time of diagnosis. At diagnosis, the ages of patients who had short stature $(7.8 \pm 4.2$ years) were significantly higher than those who did not $(5.1 \pm 4.3$ years $)(p=0.005)$.

The mean diagnosis age of patients was $6.4 \pm 4.4$ (range $1-15$ ) years, and they were followed up for $47.2 \pm 31$ (range 12-131) months. At the time of diagnosis, $33(45.2 \%)$ patients were $\leq 6$ years of age and $40(54.8 \%)$ patients were $>6$ years of age. At the diagnosis, the mean age of patients who were diagnosed $\leq 6$ years of age was $31 \pm 14$ months, while the mean age of patients who were diagnosed $>6$ years of age was $124 \pm 92$ months. Follow-up times of both groups were similar ( $48 \pm 38$ months vs $46 \pm 25$ months, respectively, $\mathrm{p}=0.27)$. A comparison of anthropometric measurements in patients who were diagnosed at $\leq 6$ years of age and $>6$ years of age was conducted. The height and weight $\mathrm{z}$-scores of the patients who were

TABLE 2. Association between age of diagnosis and anthropometric measurements

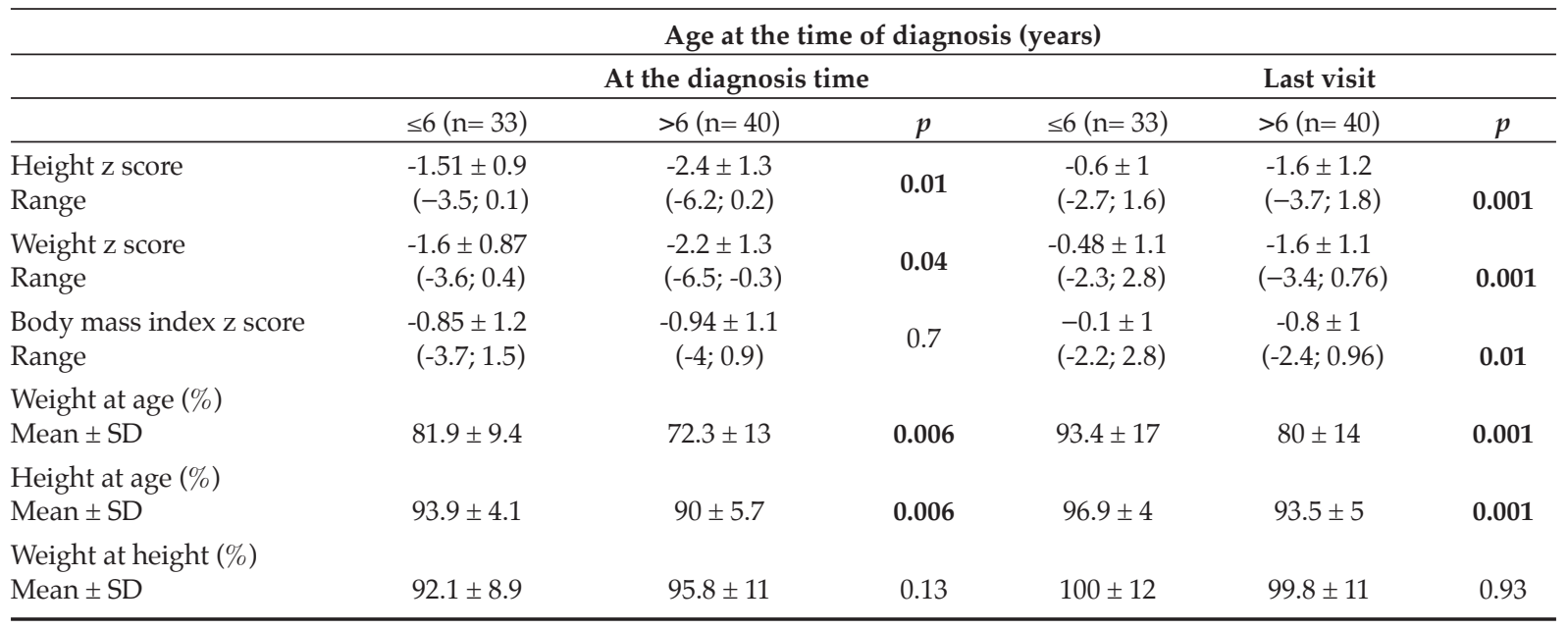

SD: standard deviation. 
diagnosed at $>6$ years of age were significantly lower than the younger group $(\mathrm{p}=0.01$ and 0.04 , respectively). When the anthropometric data of both groups in the last follow-up were compared, the height, weight, and BMI z scores of the patients who were diagnosed at after the age of 6 were significantly lower than those of the patients who were diagnosed early ( $\mathrm{p}=0.001,0.001$ and 0.01 , respectively) (Table 2). Both groups' delta growth (last SD- first SD) for height, weight, and BMI were compared. No difference was found between the growth rates of both groups (delta height: $\mathrm{p}=0.95$, delta weight $\mathrm{p}=0.15$, delta BMI $\mathrm{p}=0.52$ ).

The correlation between the diagnosis age and the anthropometric values of the patients at the time of the last visit was analysed. A slightly significant correlation was found between the age of diagnosis and the height, weight, and BMI z scores at the last visit $(r=-0.35 p=0.003 ; r=-0.46$ $\mathrm{p}<0.001 ; \mathrm{r}=-0.34 \mathrm{p}=0.003$, respectively).

Forty-five $(61.6 \%)$ patients were fully compliant with their diet (negative antibodies), whereas 28 (38.4\%) were not (positive antibodies). No significance was found between gender, celiac type, diagnosis age, and follow-up duration with dietary compliance. The mean age of the patients who were not compliant with GFD (11.6 \pm 4.2 years) was higher than that of the fully compliant patients (9.6 \pm 4.7 years), the difference between was statistically slightly significant $(\mathrm{p}=0.06)$.

Comparing the anthropometric measurements of the first and last controls of the patients according to GFD compliance, it was found that all measurements significantly improved in both groups, and no difference was found between the anthropometric measurements of children who complied with the diet and those who did not, in the last control (Table 3). When the growth rates of both groups were compared, it was found that the increase in delta weight and delta BMI of the group fully compliant was found to be significantly higher $(p=0.02, p=0.03)$, while no difference was found in the height-growth rate $(\mathrm{p}=0.88)$.

The height $\mathrm{z}$ score, weight $\mathrm{z}$ score, and BMI $z$ score in the final control in patients who were diagnosed at $\leq 6$ years of age and who showed full compliance to their diets were significantly higher than in those who showed full compliance to their diets but who were diagnosed after the age of 6 years (Table 4 ).

No difference was found between the diagnosis height $\mathrm{z}$ score of patients with typical and atypical celiac disease $(-2 \pm 1.1$ and $-2 \pm 1.3$, respectively), and their height $\mathrm{z}$ score during their last visit $(-1.1 \pm 1.1$ and $-1.1 \pm 1.3$, respectively) $(\mathrm{p}=0.824, \mathrm{p}=0.716$, respectively).

\section{DISCUSSION}

$\mathrm{CD}$ is an autoimmune enteropathy that occurs in response to permanent susceptibility to gluten in individuals with a genetic predisposition. The only treatment of the disease is lifelong GFD. ${ }^{5,12}$ To date, approximately half of the patients are diagnosed with atypical symptoms. ${ }^{13}$ About $8-10 \%$ of the patients are diagnosed when they

TABLE 3. Anthropometric measurements of patients with celiac disease according to gluten-free diet compliance

\begin{tabular}{|c|c|c|c|}
\hline & \multicolumn{2}{|c|}{ Last visit } & \multirow[b]{2}{*}{$p$} \\
\hline & $\begin{array}{l}\text { Compliance with GFD } \\
(n=45)\end{array}$ & $\begin{array}{l}\text { Non-compliance with GFD } \\
(\mathrm{n}=28)\end{array}$ & \\
\hline $\begin{array}{l}\text { Height z score } \\
\text { mean } \pm \text { SD (range) }\end{array}$ & $\begin{array}{r}-1.1 \pm 1.3 \\
(-3.7 ; 1.8)\end{array}$ & $\begin{array}{r}-1.3 \pm 1.1 \\
(-3.6 ; 1.6)\end{array}$ & 0.379 \\
\hline $\begin{array}{l}\text { Weight z score } \\
\text { mean } \pm \text { SD (range) }\end{array}$ & $\begin{array}{c}-1.05 \pm 1.3 \\
(-3.4 ; 2.8)\end{array}$ & $\begin{array}{l}-1.1 \pm 1 \\
(-3.36 ; 0.6)\end{array}$ & 0.869 \\
\hline $\begin{array}{l}\text { BMI z score } \\
\text { mean } \pm \text { SD (range) }\end{array}$ & $\begin{array}{r}-0.5 \pm 1.1 \\
(-2.4 ; 2.8)\end{array}$ & $\begin{array}{c}-0.43 \pm 0.88 \\
(-2.2 ; 0.96)\end{array}$ & 0.592 \\
\hline $\begin{array}{l}\text { Weight at age }(\%) \\
\text { mean } \pm \text { SD }\end{array}$ & $86.9 \pm 18$ & $85.3 \pm 13$ & 0.863 \\
\hline $\begin{array}{l}\text { Height at age }(\%) \\
\text { mean } \pm \text { SD }\end{array}$ & $95.5 \pm 5$ & $94.2 \pm 4$ & 0.610 \\
\hline $\begin{array}{l}\text { Weight at height }(\%) \\
\text { mean } \pm \text { SD }\end{array}$ & $98.8 \pm 12$ & $103 \pm 10$ & 0.342 \\
\hline
\end{tabular}

CD: celiac disease; GFD: gluten-free diet, SD: standard deviation. 
are investigated for short stature, and $10-40 \%$ of the patients have short stature during the diagnosis. ${ }^{14-16}$ Approximately $19-59 \%$ of the non-endocrine causes of short stature are CDdependent. ${ }^{8} 28.7 \%$ of our patients were admitted due to short stature, while $47.9 \%$ were found to have short stature at the time of diagnosis. The cause of short stature is not completely understood in patients with CD. Based on growth retardation in $\mathrm{CD}$, malabsorption and malnutrition of basic food caused by histological damage in the mucosa of the small intestine are generally responsible for this symptom. Disrupted growth hormone/insulin-like growth factor-1 axis, participation of increasing levels of inflammatory markers in serum to IGF-system dysregulation, a decrease in IGF-1 and IGF-BP-3 levels, and autoimmune hypophysitis are also among the causes. ${ }^{5,17,18}$

In this study, early diagnosis and full compliance to GFD has been shown to result in the best positive effect on children's growth parameters. Compliance to a gluten-free diet was shown to have significantly positive effects on weight and BMI z scores. however, no difference was found between the two groups in terms of height z-scores. While catch-up growth with gluten elimination is observed in children, several studies reported that anthropometric measurements are not correlated with dietary compliance. ${ }^{19}$ Radlovic et al.,${ }^{20}$ compared patients who were fully compliant and noncompliant with GFD. They found that there was improvement in the weight, height, and hemoglobin levels, but a significant difference was not found between the two groups. Jadresin et al., ${ }^{19}$ reported that a significant difference existed in the weight $\mathrm{z}$ scores of compliant and non-compliant patients but observed no significant difference in the height $\mathrm{z}$ scores. Like these studies, a significant recovery was found in the weight and BMI z-scores of the patients in the group fully compliant with GFD, no difference was found in terms of height $\mathrm{z}$-scores.

Another study found that weights of patients with late diagnosed $\mathrm{CD}$ ( $>4$ years of age) became normal with a GFD; however, in a 4-year followup, their heights were significantly lower than those who were diagnosed early (2-4 years of age). ${ }^{21}$ Weiss et al., ${ }^{22}$ reported that the final heights of patients with CD were inversely correlated with diagnosis age. Aydoğdu et al., ${ }^{23}$ found significant inverse correlation between age of diagnosis and height and weight SDS scores of patients with CD at the end of a fouryear follow-up. Similarly, in our study, there was an inverse correlation between the age of diagnosis and height, weight, and BMI z scores at the last follow-up. In Boersma B et al. ${ }^{7}$ study, it was found that the height $\mathrm{z}$-scores of children with celiac who were diagnosed after the age of 3 were about 1 SDS lower than those who were diagnosed before the age of 3 . However, catch-up growth patterns of both groups were found to be similar. Similarly, it was found in our study that the height, weight, and BMI z-scores of children diagnosed after the age of 6 were significantly lower than those of children diagnosed before the age of 6 . Although there were no differences between the growth rates (delta height, delta weight, and delta BMI) of both groups, this significant difference in growth parameters was found to continue in the last visit. In a study by Kivela et al., ${ }^{24}$ it was found that celiac patients diagnosed with screening were found to be younger than those clinically detected and their complaints were milder. In our study, the ages of children who had short stature at diagnosis

TABLE 4. Relation between the patients' diagnosis age gluten-free diet compliance and anthropometric parameters

\begin{tabular}{|c|c|c|c|c|c|c|c|c|c|}
\hline \multirow[b]{3}{*}{ Diagnosis age of patients (years) } & \multicolumn{6}{|c|}{ Last visit } & & & \\
\hline & \multicolumn{3}{|c|}{ Height z score } & \multicolumn{3}{|c|}{ Weight z score } & \multicolumn{3}{|c|}{ BMI z score } \\
\hline & $\begin{array}{c}\leq 6 \\
(n=33)\end{array}$ & $\begin{array}{c}>6 \\
(n=40)\end{array}$ & $p$ & $\begin{array}{c}\leq 6 \\
(n=33)\end{array}$ & $\begin{array}{c}>6 \\
(n=40)\end{array}$ & $p$ & $\begin{array}{c}\leq 6 \\
(n=33)\end{array}$ & $\begin{array}{c}>6 \\
(n=40)\end{array}$ & $p$ \\
\hline Compliance with GFD* $(n=45)$ & $\begin{array}{c}-0,6 \pm 0.9 \\
-0,7 \\
(2.7 ; 1.1)\end{array}$ & $\begin{array}{c}-1,5 \pm 1.4 \\
-1,2 \\
(-3.7 ; 1.8)\end{array}$ & 0.016 & $\begin{array}{c}-0.34 \pm 1.1 \\
-0.39 \\
(-2.31 ; 2.8)\end{array}$ & $\begin{array}{c}-1.8 \pm 1 \\
-1.9 \\
(-3.4 ; 0.7)\end{array}$ & 0.001 & $\begin{array}{c}0.02 \pm 1.2 \\
-0.03 \\
(-2.2 ; 2.8)\end{array}$ & $\begin{array}{c}-1 \pm 0.9 \\
-1.3 \\
(-2.4 ; 0.7)\end{array}$ & 0.001 \\
\hline Non-compliance with GFD* $(n=28)$ & $\begin{array}{c}-0.75 \pm 1.2 \\
-1 \\
(-2.5 ; 1.6)\end{array}$ & $\begin{array}{c}-1.6 \pm 1 \\
-1.6 \\
(-3.6 ; 0.1)\end{array}$ & 0.041 & $\begin{array}{c}-0.8 \pm 0.6 \\
-0.73 \\
(-1.6 ; 0.3)\end{array}$ & $\begin{array}{c}-1.2 \pm 1.1 \\
-1.1 \\
(-3.3 ; 0.6)\end{array}$ & 0.276 & $\begin{array}{c}-0.32 \pm 0.5 \\
-0.45 \\
(-0.94 ; 0.5)\end{array}$ & $\begin{array}{c}-0.4 \pm 0.9 \\
-0.36 \\
(-2.1 ; 0.9)\end{array}$ & 0.790 \\
\hline$p$ & 0.758 & 0.763 & & 0.237 & 0.137 & & 0.248 & 0.02 & \\
\hline
\end{tabular}

*mean \pm standard deviation, median, range; GFD: gluten-free diet. 
were found to be significantly higher than those who did not. Despite increased awareness and screening programs, delays of about 7-10 years occur in the diagnosis of celiac disease. ${ }^{25,}{ }^{26}$ Delays in treatment initiation for children with celiac disease are known to be associated with short adult height. ${ }^{9}$ In a study conducted recently, it was found that adult celiac patients were significantly shorter when compared with their peers. ${ }^{27}$ A study by Saari et al., ${ }^{8}$ showed that a slow growth occurs in children with $\mathrm{CD}$ prior to diagnosis. They emphasized that growth retardation is the earliest and most important diagnosis of $\mathrm{CD}$.

After starting a GFD, a rapid, catch-up growth occurs, particularly in the first six months. Weight catch-up is much faster than height catch-up. ${ }^{4}$ Catch-up growth is a remarkable phenomenon characterized by a supranormal height velocity, following a transient period of growth inhibition.? During catch-up, the child may grow in height at up to four times the average rate for his or her chronological age. ${ }^{21}$ Catch-up growth is not only observed after onset of GFD in a child with celiac disease, but also observed after recovery from various other disorders, such as malnutrition and osteoporosis. ${ }^{7}$ Variability may be related to GFD adherence and age at diagnosis, delays in which can lead to slower and more incomplete catchup growth. In a study, children diagnosed after 4 years of age showed slower and incomplete catch-up growth. ${ }^{22}$ Catch-up in height in severely stunted children takes a relatively longer time, and patients whose conditions are diagnosed late show slower and incomplete catch-up growth, In addition, in celiac disease, multiple alterations in the growth axis and partial growth hormone insensitivity occur during the active phase of the disease. ${ }^{4,21}$ The significant decrease in height among patients with $\mathrm{CD}$ who were diagnosed late in our study may be related to aforementioned information.

Dietary compliance in patients with CD is difficult, especially in adolescent patients. Dietary compliance of patients who are diagnosed in the adolescence stage or asymptomatic patients is worse than that of patients with classical symptoms and of patients who are diagnosed in early childhood. ${ }^{28}$ Several studies showed high levels of compliance to GFD, such as $75 \%{ }^{29}$ but lower values between $44 \%$ and $58 \%$ were also observed. ${ }^{18,25}$ Similar to other studies, a $61.6 \%$ full compliance rate was found in this study. In our study, the ages of patients non-compliant with gluten-free diet were found to be higher than those of patients who were fully compliant with gluten-free diet. This result shows that diet is negatively affected in adolescence. GFD is not only related with food intake in individuals, it is also associated with lifestyle and life quality. ${ }^{30}$ Noncompliance may be experienced during social events, such as physiological changes, travel, and eating out in adolescence. Clinicians have difficulty in following up and evaluating this condition..$^{28}$ Thus, adult celiac patients should be closely followed in terms of compliance with the diet, and they should be encouraged.

The limitation of our study was that the assessment was not conducted with the final height of the patients because they were all in adolescence stage at the last visit. Assessment with the final height can be produced more significant results, In addition, the small number of patients in each group may have caused statistically insignificant results. Other factors that influence adherence to the diet, such as education and socioeconomic level, are not considered.

\section{CONCLUSIONS}

In conclusion, delay in CD diagnosis negatively affected both the height and weight and other growth parameters. GFD compliance positively affected the patients' all growth parameters, especially weight and BMI z-score.

\section{REFERENCES}

1. Maki M. Celiac disease. In: Kleinman RE, Sanderson IR, GouletOJ, et aleds. Walker's Pediatric Gastrointestinal Disease. 5th ed. Shelton CT: People's Medical Publishing House; 2008.P.319-28.

2. Kang JY, Kang AH, Green A, et al. Systematic review: Worldwide variation in the frequency of celiac disease and changes over time. Aliment Pharmacol Ther 2013;38(3): 226-45.

3. Dalg1ç B, SariS, Basturk B, et al. Prevalence of celiac disease in healthy Turkish school children. Am J Gastroenterol 2011;106(8):1512-7.

4. Troncone R, Kosova R. Short stature and catch-up growth in celiac disease. J Pediatr Gastroenterol Nutr 2010;51 (Suppl 3):137-8.

5. Guandalini S. Celiac disease. In: Guandalini S, ed. Essential Pediatric Gastroenterology, Hepatology E Nutrition. New York: McGraw-Hill; 2005.P.221-30.

6. Lebenthal E, Shteyer E, Branski D. The changing clinical presentation of celiac disease. Pediatr Adolesc Med 2008; 12:18-22.

7. Boersma B, Houwen RH, Blum WF, et al. Catch-up growth and endocrine changes in childhood celiac disease. Endocrine changes during catch-up growth. Horm Res 2002;58 (Suppl 1):57-65.

8. Saari A, Harju S, Mäkitie O, et al. Systematic growth monitoring for the early detection of celiac disease in children. JAMA Pediatr 2015;169(3):e1525. 
9. Scherdel P, Dunkel L, van Dommelen P, et al. Growth monitoring as an early detection tool: a systematic review. Lancet Diabetes Endocrinol 2016;4(55):447-56.

10. GuandaliniS, Setty M.Celiacdisease.Curr Opin Gastroenterol 2008;24(6):707-12.

11. Oberhuber G, Granditsch G, Vogelsang H. The histopathology of celiac disease: Time for a standardized report scheme for pathologists. Eur J Gastroenterol Hepatol 1999;11(10):1185-94.

12. Moore JK, West SR, Robins G. Advances in celiac disease. Curr Opin Gastroenterol 2011;27(2):112-8.

13. Admou B, Essaadouni L, Krati K, et al. Atypical celiac disease: From recognizing to managing. Gastroenterol Res Pract 2012;2012:637187.

14. Haapalahti M, Kulmala P, Karttunen TJ, et al. Nutritional status in adolescents and young adults with screen-detected celiac disease. J Pediatr Gastroenterol Nutr 2005;40(5):566-70.

15. Balamtekin N, Uslu N, Baysoy G, et al. The presentation of celiac disease in 220 Turkish children. Turk J Pediatr 2011;52(3):239-44.

16. Ravikumara M, Tuthill DP, Jenkins HR. The changing clinical presentation of coeliac disease. Arch Dis Child 2006;91(12):969-71.

17. Nurminen S, Kivelä L, Taavela J, et al. Factors associated with growth disturbance at celiac disease diagnosis in children: A retrospective cohort study. BMC Gastroenterol 2015;15:125.

18. Meazza C, Pagani S, Laarei K, et al. Short stature in children with celiac disease. Pediatr Endocrinol Rev 2009;6(4):457-63.

19. Jadresin O, Misak Z, Kolacek S, et al. Compliance with gluten-free diet in children with celiac disease. J Pediatr Gastroenterol Nutr 2008;47(3):344-8.

20. Radlović N, Mladenović M, LekovićZ, et al. Effect of glutenfree diet on the growth and nutritional status of children with coeliac disease. Srp Arh Celok Lek 2009;137(11-12):632-7.
21. Patwari AK, Kapur G, Satyanarayana L, et al. Catch-up growth in children with late-diagnosed celiac disease. $\mathrm{Br}$ J Nutr 2005;94(3):437-42.

22. Weiss B, Skourikhin Y, Modan-Moses D, et al. Is adult height of patients with celiac disease influenced by delayed diagnosis? Am J Gastroenterol 2008;103(7):1770-4.

23. Aydogdu S, Midyat L, Cakir M, et al. Long-term effect of gluten-free diet on growth velocity in Turkish children with celiac disease. Dig Dis Sci 2009;54(10):2183-7.

24. Kivelä L, Kaukinen K, Huhtala H, et al. At-risk screened children with celiac disease are comparable in disease severity and dietary adherence to those found because of clinical suspicion: a large cohort study. J Pediatr 2017;183:115-21.e2.

25. Fuchs V, Kurppa K, Huhtala H, et al. Factors associated with long diagnostic delay in celiac disease. Scand J Gastroenterol 2014;49(11):1304-10.

26. Vayricka SR, Vadasz N, Stotz M, et al. Celiac disease diagnosis still significantly delayed- Doctor's but not patients' delay responsive for the increased total delay in women. Dig Liver Dis 2016;48(10):1148-54.

27. Esmaeilzadeh A, Ganji A, Goshaveshi L, et al. Adult celiac disease: Patients are shorter compared with their peers in the general population. Middle East J Dig Dis. 2016;8(4): 303-9.

28. Guandalini S, Assiri A. Celiac disease: a review. JAMA Pediatr 2014;168(3): 272-8.

29. Chauhan JC, Kumar P, Dutta AK, et al. Assessment of dietary compliance to gluten free diet and psychosocial problems in Indian children with celiac disease. Indian J Pediatr. 2010;77(6):649-54.

30. Roma E, Roubani AE, Kolia E, et al. Dietary compliance and life style of children with celiac disease. J Hum Nutr Diet 2010;23(2):176-82. 